\title{
Prevalence of Geriatric Malnutrition in Long Term Care Center in Riyadh/Saudi Arabia: A Cross Sectional Study
}

\section{Maha Al Turki ${ }^{1,2 *}$, Noura Al Sibaie ${ }^{1}$, Hind Al Otaibi ${ }^{1}$, Ghadeer Al Ammari $^{1}$ and Raghad Al Otaibi ${ }^{1}$}

${ }^{1}$ Clinical Nutrition Program, College of Applied Medical Sciences/King Saud bin

Abdulaziz University for Health Sciences (KSAU-hs), Riyadh, Saudi Arabia

${ }^{2}$ King Abdullah International Medical Research Center (KAIMRC), Riyadh, Saudi

Arabia

*Corresponding Author: Maha Al Turki, College of Applied Medical Sciences, King Saud bin Abdulaziz University for Health Sciences (www.ksau-hs.edu.sa) and King Abdulaziz Medical City, National Guard Health Affairs, Saudi Arabia.

DOI: 10.31080/ASNH.2020.05.0807
Received: December 14, 2020

Published: January 16, 2021

(C) All rights are reserved by Maha Al Turki., et al.

\section{Abstract}

Background: Older adults are more vulnerable to malnutrition and multiple nutritional deficiencies due to several age-related physiological and functional changes. The prevalence of malnutrition among institutionalized elderly is estimated to be between 30\%-60\%; therefore, accurate nutritional assessment is important for both effective diagnosis and intervention of comprehensive treatment plans for older people.

Objective: To assess the nutritional status of institutionalized elderly female in Riyadh city, and to explore the association between their nutritional statuses and other determinants such as their mobility status and mood of feeding.

Method: Cross-sectional study of 38 females aged 60 years and over who currently resident at the Social Welfare Home for Elderly Females in Riyadh/ Saudi Arabia. Anthropometric/biochemical data, medications, and length of residency were retrieved form medical records of the resident. Nutritional status was assessed using Mini Nutritional Assessment (MNA) tool.

Results: More than $94 \%$ of the residents were malnourished or at risk of developing malnutrition. Twenty one percent of the resident were underweight (BMI below $18.5 \mathrm{~kg} / \mathrm{m} 2$ ) and $60 \%$ of them were categorized as overweight/obese (BMI above $25 \mathrm{~kg} / \mathrm{m} 2$ ). Significantly greater percentage of malnourished residents were dependent for mobility $(\mathrm{p}<0.001)$ or require assistant during feeding $(p=0.023)$. Physical dependency was an independent predictor of the nutritional status among our sample $(\beta=2.375$; SE 0.800 ; $\mathrm{p}=0.006)$.

Conclusion: According to several nutritional assessment methods, the majority of institutionalized elderly females at the Social Welfare Home for Elderly Females in Riyadh were malnourished or at risk of developing malnutrition. This study underlines the association between nutritional status and physical dependencies among this age group. Strategies for effective nutritional care should be implemented for institutionalized older adults to treat and prevent the malnutrition and to improve the quality of life for them.

Keywords: Nutritional Status; Malnutrition; Nutritional Assessment; Institutionalized Elderly; Geriatric Assessment 


\section{Abbreviations}

BMI: Body Mass Index, MNA: Mini Nutritional Assessment.

\section{Introduction}

The nutritional status of elderly is an important factor in maintain a healthy aging for the individual and reducing the progression of chronic disease. During the ageing process, several physiological changes may occur and affect the health status of an elderly such as; loss of appetite, difficulties in swallowing and chewing, and loss of teeth [1]. As a result of these physiological and functional changes, older adults are more vulnerable to be malnourished and to develop multiple nutritional deficiencies compared to other adult populations [2].

Reported malnutrition prevalence among elderly in nursing homes is estimated to be between $30 \%-60 \%$ [3,4]. However, this prevalence dropped to $10 \%$ among free-living older adults [5]. This variation in the prevalence is vary not only to the type of living status of the elderly (institutionalized vs free-living) but also due to the differences in the study population and the criteria used to assess the nutritional status.

There is a large volume of published studies describing the nutritional status of older adults and exploring the effect of aging on their nutritional status [6,7]. Age-related changes in the digestive tract was reported to be the main reason that can cause malnutrition among older people [8]. Also, studies have linked between age and loss of appetite and consider this as an important factor that increase the risk of malnutrition [9]. Older adults usually have less hunger sensation and feel full immediately which may negatively reflect on their energy intake compared to their energy expenditure. All international studies have shown that various causes of malnutrition among the elderly were chronic diseases, and other factors like taking drugs which can cause malabsorption of nutrients and changes in the motility of digestive tract [10]. Another reason was oral problems such as loss of teeth or poorly suitable dentures [11]. Researchers have found that being underweight or overweight are serious issues among elderly population. Also, many studies have concluded that there are differences between elderly regarding the nutritional status, whereas overweight is positively associated more with the female gender [12]. Also, smoking, alcohol consumption, and excessive use of medication can affect the nutritional status of elderly [13]. Underweight is more prevalent among elderly who used up to two medications and overweight is less common among those who are smokers. Moreover, many studies have indicated that most elderly have poor health and socio-economic status and low level of education [14]. Additionally, researchers have found that elderly women have lower level of education than men; however, elderly males have chronic diseases than females [15].

Although extensive research has been carried out worldwide exploring the nutritional status of initialized elderly, very limited similar studies exists in Saudi Arabia. The nutritional intervention of elderly is often ignored in Saudi Arabia while the majority of intervention programs are focused more on other age groups. Unfortunately, there are limited number of studies evaluated the economic cost estimate of under-nutrition of older people. Hence the present study was planned to assess the nutritional status and to determine the prevalence of malnutrition in elderly female residents in longterm care center in Riyadh. Also, it aimed to explore the association between their nutritional status and other determinants.

\section{Materials and Methods}

Ethical approval for this cross-sectional study was obtained from King Abdullah International Medical Research Center (KAIMRC)/ Ministry of National Guard- Health Affairs (SP17/242/R). The study was conducted during the period from October to November 2017 at the Social Welfare Home for Elderly Females which is under the supervision of the Department of Social Welfare and Family. Permission to conduct the research at the Social Welfare Home was gained from the Saudi Ministry of Labor and Social Department.

There are two gender-segregated Social Welfare Homes for Elderly in Riyadh city. They hosts older adult members and provides them with a family atmosphere as possible including all the requirements for full substance and clothing. In addition, it provides them with numbers of properties, programs, and services for education, health, social, physiological, and culture programs.

Study subjects

Non-probability convenient sampling technique was used to choose the sample for the present study. Subjects who were aged 
$\geq 60$ years with good cognitive status and currently reside in the social welfare home in Riyadh were included. Any subjects who were critically ill, receiving enteral or parenteral nutrition and/or having cognitive impairment were excluded from the study. Verbal informed consent was obtained from all subjects before collecting the data. Subjects were approached based on cooperation with nurses and the dietitian working in the social welfare home.

\section{Data collection}

\section{Anthropometric and biochemical measurements}

A list of potential subjects $(n=62)$ was obtained by accessing the records for all female residents. Initial assessment of all eligible subjects' was carried out by a researcher and the Social Welfare Homes nurse. Resident numbers and hospital patient database numbers were documented into one master-list to crosscheck the original records if required. Then data was retrieved from the eligible female subjects' medical records that includes; blood analysis test, anthropometric measurements, medications, and length of residency.

\section{Mini nutritional assessment (MNA)}

The Mini Nutritional Assessment (MNA) is the most established nutritional assessment tool to detect malnutrition among elderly population [16]. The validated Arabic version of the MNA was used for single and rapid assessment of the nutritional status, mobility status, and dietary parameters and to identify who is at risk of malnutrition. This tool has high sensitivity and validity for elderly population [17]. It contains brief 18 questions divided into: anthropometric measurements, dietary habits, global assessment and subjective evaluation. The sum of the MNA score (total=30 points) would distinguish between older female with normal nutritional status (MNA score $\geq 22$ ), who are at risk of malnutrition (MNA score= between 15 and 21.5), or malnourished (MNA score $\leq 15)[17]$.

\section{Statistical analysis}

The Data were analyzed using SPSS for windows (Statistical Package for Social Sciences V 22.00). Data was entered and re- vised by two researchers to maintain accuracy and minimize typing error. The mean and Standard Deviation SD was used to present numerical data, and percentage was used categorical variables. Various statistics tests such as chi-square test, correlation statistics were employed to analyze the data. A p-value of less than 0.05 was considered as significant.

\section{Results and Discussion}

Characteristics of the study sample

Out of the 62 residents in the Social Welfare Home in Riyadh city, only 38 older females were eligible to be included in the study based on the decided inclusion criteria. The basic characteristics presented by mean and standard deviation for the total sample are shown in table 1 . The mean age of the sample was $64 \pm 12.19$ years and their mean BMI was $30 \pm 7.43 \mathrm{~kg} / \mathrm{m}^{2}$. Thirty seven percent of the subjects were Bed/chair bound and $37 \%$ have limited mobility and required help in some activity such as dressing and using the bathroom. More than two fifth of the sample were unable to consume food without assistant. The food intake was severely decreased in more than half of the sample in the 3 months prior to data collection. The mean length of the stay in the long-term care center was $11 \pm 7.159$ year.

\section{Nutritional status of the study sample}

The results of the assessment of nutritional status according to anthropometric/ biochemical variables and MNA tool are expressed in Table 2. Of the 38 residents, only $18 \%$ of them were found to have normal BMI values (18.5 $-24.9 \mathrm{~kg} / \mathrm{m}^{2}$ ), where $21 \%$ of them were categorized as underweight (below $18.5 \mathrm{~kg} / \mathrm{m}^{2}$ ). The majority of the study sample (60\%) were found to be overweight/ obese (above $25 \mathrm{~kg} / \mathrm{m}^{2}$ ).

As determined by the MNA tool, the prevalence of malnutrition among the study sample was $26 \%$, and risk of malnutrition was detected in $68 \%$. Only $5 \%$ of the resident were found to have normal nutritional status according to this assessment tools.

Although the mean value for serum albumin was in the normal range, 8 subjects (21\%) had albumin status below $35 \mathrm{~g} / \mathrm{l}$. Total protein and hemoglobin were below the desirable values in 11 (29\%) and 13 (34\%) subjects respectively. Fourteen subjects (37\%) were 


\begin{tabular}{|c|c|}
\hline Characteristics & $\begin{array}{l}\text { Data expressed as a } \\
\text { mean }( \pm S D) \text { or } n(\%)\end{array}$ \\
\hline Age (years) & $63.6 \pm 12.19$ \\
\hline Height $(\mathrm{cm})$ & $148.9 \pm 8.751$ \\
\hline Weight (kg) & $63.3 \pm 16.733$ \\
\hline BMI $\left(\mathrm{kg} / \mathrm{m}^{2}\right)$ & $29.7 \pm 7.434$ \\
\hline Admission Duration (years) & $10.7 \pm 7.159$ \\
\hline Weight loss during the last 3 months & $4.4 \pm 0.802$ \\
\hline Total MNA Score & $16.97 \pm 3.223$ \\
\hline \multicolumn{2}{|l|}{$\begin{array}{l}\text { Food intake over the last } 3 \text { months } \\
\qquad(\mathrm{n})^{*}\end{array}$} \\
\hline Sever decrease & $53 \%(20)$ \\
\hline Moderate decrease & $26 \%(10)$ \\
\hline No decrease & $21 \%(8)$ \\
\hline \multicolumn{2}{|l|}{ Mobility status \% (n) * } \\
\hline Dependent & $37 \%(14)$ \\
\hline Limited mobility & $37 \%(14)$ \\
\hline Independent & $26 \%(10)$ \\
\hline \multicolumn{2}{|l|}{ Mood of feeding \% (n) } \\
\hline Unable to eat without assistant & $42 \%(16)$ \\
\hline Self-fed with some difficulty & $16 \%(6)$ \\
\hline Self-fed without any problem & $42 \%(16)$ \\
\hline
\end{tabular}

Table 1: General characteristics of study population $(n=38)$.

MNA: Mini Nutritional Assessment (total score $=30$ )

*Dependent: Bed/chair bound. Limited mobility: Require some assistance with some mobility activity such as dressing and toileting. Independent: Able to perform mobility activity safely without assistant.

found to have cholesterol status below the reference value of 5.2 mmo/l.

Association between the nutritional status (rated by MNA) with mobility status and mode of feeding among the study sample

A statistically significant difference was observed between the malnourished subjects and the subjects with the risk of malnutrition (rated by MNA) with regards to mobility $(\mathrm{p}<0.001)$ and mood of feeding ( $p=0.023$ ) (Table 3$)$. The majority of dependent subjects (bed/chair bound) were found to be malnourished (91\%),

\begin{tabular}{|c|c|}
\hline Indicators of nutritional status & \% (n) \\
\hline Anthropometric assessment (BMI) & \\
\hline $\mathrm{BMI}<18.5$ & $21 \%(8)$ \\
\hline $18.5<\mathrm{BMI}>24.9 \mathrm{~kg} / \mathrm{m}^{2}$ & $18 \%(7)$ \\
\hline $25<\mathrm{BMI}>29.9 \mathrm{~kg} / \mathrm{m}^{2}$ & $18 \%(7)$ \\
\hline $30<\mathrm{BMI}>34.9 \mathrm{~kg} / \mathrm{m}^{2}$ & $15.5 \%(4)$ \\
\hline BMI $>35 \mathrm{~kg} / \mathrm{m}^{2}$ & $18 \%(7)$ \\
\hline Biochemical assessment $*$ & $21 \%(8)$ \\
\hline Albumin $(\mathrm{g} / \mathrm{l})$ & $29 \%(11)$ \\
\hline Total protein (g/l) & $34 \%(13)$ \\
\hline Hemoglobin (g/l) & $37 \%(14)$ \\
\hline Cholesterol (mmo/l) & \\
\hline Nutritional status rated with the MNA $* *$ & $5 \%(2)$ \\
\hline Normal \% (n) & $26 \%(10)$ \\
\hline Malnourished \% (n) & $68 \%(26)$ \\
\hline At risk of malnutrition \% (n) & \\
\hline
\end{tabular}

Table 2: Assessment of the nutritional status according to several indicators.

*Percentage of subjects with values outside the define reference range. Reference values: Albumin: 35-55 g/l, Total protein: 60 $83 \mathrm{~g} / \mathrm{l}$, Hemoglobin: 12.0 - $15.5 \mathrm{~g} / \mathrm{dl}$, Cholesterol: below than 5.2 $\mathrm{mmo} / \mathrm{l}$.

**MNA score range; Normal status: 24 to 30, Risk of malnutrition: 17 to 23.5, Malnourished: less than 17.

whereas no one among the independent ones were having malnutrition. Also, almost three-quarters of subjects (73\%) who require a full assistant in feeding among our sample were malnourished. This percentage dropped to only $9 \%$ when the subjects were totally dependent in the eating process.

Multiple regression analysis with the nutritional status (rated by MNA) as dependent variables

In the correlation analysis, the nutritional status of the sample (rated by MNA score) correlated with the BMI ( $\mathrm{r}=0.37, \mathrm{p}=0.033)$, mobility status $(\mathrm{r}=0.633, \mathrm{p}<0.001)$ and the subjects mood of feeding $(r=0.371, p=0.022)$.

Multiple regression analysis for the subjects nutritional status (rated by MNA score) as a dependent variable indicate that the mo- 


\begin{tabular}{|c|c|c|c|}
\hline \multirow{2}{*}{ Variables } & \multicolumn{2}{|c|}{ Nutritional Status* } & \multirow{2}{*}{ \% (n) } \\
\cline { 2 - 4 } & Malnourished \% (n) & At risk of malnutrition \% (n) & \multirow{2}{*}{$<0.001$} \\
\hline Mobility Status & & & $37 \%(14)$ \\
\hline Dependent & $91 \%(10)$ & $15 \%(4)$ & $37 \%(14)$ \\
\hline Limited mobility & $9 \%(1)$ & $48 \%(13)$ & $26 \%(10)$ \\
\hline Independent & $0 \%(0)$ & $37 \%(10)$ & 0.023 \\
\hline Mood of feeding & & & $42 \%(16)$ \\
\hline Unable to eat without assistant & $73 \%(8)$ & $30 \%(8)$ & $16 \%(6)$ \\
\hline Self-fed with some difficulty & $18 \%(2)$ & $15 \%(4)$ & $42 \%(16)$ \\
\hline
\end{tabular}

Table 3: Correlation between nutritional status of study sample and mobility status and the mood of feeding.

*According to the Mini Nutritional Assessment score.

bility status ( $\beta=2.375$; SE 0.800$)$ of the resident was positively associated $(p=0.006)$ with the nutritional status (Table 4$)$.

\begin{tabular}{|c|c|c|c|c|}
\hline $\begin{array}{c}\text { Dependent } \\
\text { variable }\end{array}$ & $\begin{array}{c}\text { Independent } \\
\text { variables }\end{array}$ & $\boldsymbol{\beta}$ & SE & $\boldsymbol{p}$ \\
\hline $\begin{array}{c}\text { Nutritional } \\
\text { status* }\end{array}$ & BMI & 0.055 & 0.073 & 0.460 \\
\cline { 2 - 5 } & Mobility status & 2.375 & 0.800 & 0.006 \\
\cline { 2 - 5 } & Mood of feeding & -0.464 & 0.698 & 0.511 \\
\hline
\end{tabular}

Table 4: Predictors of the nutritional status among study sample.

*According to the MNA score.

Adjusted R square of the model= 0.315 .

However, the subjects BMI and the mood of feeding did not contribute significantly to the nutritional status of the female residents.

\section{Discussion}

The prevalence of malnutrition among institutionalized older adults shows an increasing trend worldwide [4,5]. The aim of this cross-sectional study was to evaluate the nutritional status of institutionalized elderly female living in Riyadh city. The assessment using MNA scoring have showed that $26 \%$ of the residents were malnourished and $68 \%$ were at a risk of developing malnutrition. This parentage was greater than what was detected using the same tools in previous studies [18,19].
The biochemical variables of our sample showed that mean albumin was in lower range of the reference values and was deficient in $20 \%$ of subjects. Hypoalbuminemia may reflect an acute or chronic condition that requires medical, and nutritional intervention. Low albumin level is an important indicator of malnutrition, and some studies confirmed the association between hypoalbuminemia and malnourishment [20]. Also low levels of hemoglobin in $34 \%$ of the sample indicate a high risk of developing iron-deficiency anemia. Anemia is probably multifactorial, but malnutrition seems to have a significant role. In this study, the mean of hemoglobin were in the minimum borderlines which may be a consequence of malnutrition.

One of the most interesting results of our study is the high percentage of malnourished cases among elderly who were dependent for mobility $(p<0.001)$. This is consistent with that of Lim (2018) who stated that well-nourished subjects had better muscular strength and better movement compared to malnourished group [21]. As they cannot move, they are totally dependent on caregivers who might be the reason for the increased percentage of malnutrition. This finding may partly be also explained by the association between the health status and appetite which in turn contributes to inadequate nutritional intake and malnutrition [22]. Moreover, some studies suggested increasing the incident of depression among disabled elderlies as an explanation for this relation [23]. Being bounced to wheelchair or bed will disrupt the 
elderly's ability to live an independent life and may increase the chances of developing depression and altering the cognitive function. Emotions were reported previously to be an independent predictor of dietary intake among institutionalized elderly [24]. Further regression analysis showed that the mobility status independently predict the nutritional status among our sample. This finding corroborate those of a previous study conducted on older adults $[25,26]$.

Another important finding was the significant association observed between the mode of feeding and nutritional status $(\mathrm{p}=$ 0.023). Seventy three percent of the study population, who are unable to eat without assistance, were malnourished. Usually elderly who cannot eat without assistance, cannot decide what they eat, or they have less appetite. Self-feeding difficulties is common among elderly due to stroke, vision impairment and dementia.

Unfortunately due to the cross sectional design of this study, no conclusion of causality could be drawn, and therefore it was impossible to identify if the nutritional status was the cause or consequence. Therefore, all possibilities of the relation should be taken into consideration in futures researches. Notwithstanding the relatively limited sample size, this work offers valuable insights into the nutritional status of elderly female living in long term care center in Riyadh. Considerably more work will need to be conducted to determine the prevalence of malnutrition among larger sample of elderly living in long term care centers in Saudi Arabia.

Regular nutrition assessment in long term care center is recommended to detect individuals' who are malnourished or at risk of developing malnutrition. Accurate identification and early detection of malnutrition will allow sufficient attention and appropriate intervention to be done, while any failure to recognize these cases may result in increasing the prevalence of malnutrition and related chronic diseases. Moreover, a training programs should be provided for the caregiver to improve the quality of feeding techniques and to maintain healthy nutritional status for the older adults.

\section{Conclusion}

According to several nutritional assessment methods, the majority of institutionalized elderly females at the Social Welfare
Home for Elderly Females in Riyadh were malnourished or at risk of developing malnutrition. This study underlines the association between nutritional status and physical dependency among this age group. Strategies for effective nutritional care should be implemented for institutionalized older adults to treat and prevent malnutrition and to improve the quality of life for them.

\section{Acknowledgements}

We would like to extend our sincere gratitude and appreciation for all the support and dedication provided by the staff and the residents at the Social Welfare Home for Elderly Females in Riyadh/ Saudi Arabia.

\section{Conflict of Interest}

The authors declare that they have no competing interest.

\section{Bibliography}

1. WHO | Nutrition for older persons. Who.int. (2017).

2. Verwijs MH., et al. "Interdisciplinary communication and collaboration as key to improved nutritional care of malnourished older adults across health-care settings - A qualitative study". Health Expectations (2020): 10.

3. Yang LJ., et al. "Nutrition, Physical Exercise, and the Prevalence of Sarcopenia in Elderly Residents in Nursing Homes in China". Medical Science Monitor 25 (2019): 4390-4399.

4. Khoddam H., et al. "Prevalence of Malnutrition among Elderly People in Iran: Protocol for a Systematic Review and MetaAnalysis". JMIR Research Protocol 8.11 (2019): e15334.

5. Rojer AG., et al. "The prevalence of malnutrition according to the new ESPEN definition in four diverse populations". Clinical Nutrition 35.3 (2016): 758-762.

6. Soenen S., et al. "The ageing gastrointestinal tract". Current Opinion in Clinical Nutrition and Metabolic Care 19.1 (2016): 12-18.

7. Kritchevsky SB. "Nutrition and Healthy Aging". The Journals of Gerontology: Series A 71.10 (2016): 1303-1305.

8. Bell CL., et al. "Malnutrition in the nursing home". Current Opinion in Clinical Nutrition and Metabolic Care 18.1 (2015): 17-23. 
9. Acar Tek $\mathrm{N}$ and Karaçil-Ermumcu MŞ. "Determinants of Health Related Quality of Life in Home Dwelling Elderly Population: Appetite and Nutritional Status". Journal of Nutrition, Health and Aging 22.8 (2018): 996-1002.

10. Besora-Moreno M., et al. "Social and Economic Factors and Malnutrition or the Risk of Malnutrition in the Elderly: A Systematic Review and Meta-Analysis of Observational Studies". Nutrients 12.3 (2020): 737.

11. Kossioni AE. "The Association of Poor Oral Health Parameters with Malnutrition in Older Adults: A Review Considering the Potential Implications for Cognitive Impairment". Nutrients 10.11 (2018): 1709.

12. Özkaya I and Gürbüz M. "Malnourishment in the overweight and obese elderly. Desnutrición en el anciano con sobrepeso y obesidad". Nutrición Hospitalaria 36.1 (2019): 39-42.

13. Boulos C., et al. "The AMEL study, a cross sectional populationbased survey on aging and malnutrition in 1200 elderly Lebanese living in rural settings: Protocol and sample characteristics". BMC Public Health 12.13 (2013): 573.

14. Schoufour JD., et al. "Socio-economic indicators and diet quality in an older population”. Maturitas 107 (2018): 71-77.

15. Doumit JH., et al. "Nutritional and health status among nursing home residents in Lebanon: comparison across gender in a national cross-sectional study". BMC Public Health 14 (2014): 629.

16. Abd Aziz NAS., et al. "Assessing the nutritional status of hospitalized elderly". Clinical Interventions in Aging 12 (2017): 1615-1625.

17. Vellas B., et al. "The Mini Nutritional Assessment (MNA) and its use in grading the nutritional state of elderly patients". $\mathrm{Nu}$ trition 15.2 (1999): 116-122.

18. Hallaj FA. "Assessment of the nutritional status of residents in homes for the elderly in Lattakia, Syrian Arab Republic". Eastern Mediterranean Health Journal 21.10 (2018): 753-761.

19. Agarwalla R., et al. "Assessment of the nutritional status of the elderly and its correlates". Journal of Family and Community Medicine 22.1 (2015): 39-43.
20. Brock F., et al. "Prevalence of hypoalbuminemia and nutritional issues in hospitalized elders". Revista Latino-Americana de Enfermagem 24 (2016): e2736.

21. Lim EJ. "Factors Influencing Mobility Relative to Nutritional Status among Elderly Women with Diabetes Mellitus". Iranian Journal of Public Health 47.6 (2018): 814-823.

22. Andreae C., et al. "Depressive Symptoms Moderate the Association Between Appetite and Health Status in Patients with Heart Failure". Journal of Cardiovascular Nursing 33.2 (2018): E15-E20.

23. Ahmadi SM., et al. "Dependence of the geriatric depression on nutritional status and anthropometric indices in elderly population". Iranian Journal of Psychiatry 8.2 (2013): 92-96.

24. Paquet C., et al. "Direct and indirect effects of everyday emotions on food intake of elderly patients in institutions". Journal of Gerontology: Biological Sciences 58.2 (2003): 153-158.

25. Ülger Z., et al. "Comprehensive assessment of malnutrition risk and related factors in a large group of community-dwelling older adults". Clinical Nutrition 29.4 (2010): 507-511.

26. Nykänen I., et al. "Nutritional screening in a population-based cohort of community-dwelling older people". European Journal of Public Health 23.3 (2013): 405-409.

\section{Assets from publication with us}

- Prompt Acknowledgement after receiving the article

- Thorough Double blinded peer review

- Rapid Publication

- Issue of Publication Certificate

- High visibility of your Published work

Website: www.actascientific.com/

Submit Article: www.actascientific.com/submission.php Email us: editor@actascientific.com

Contact us: +919182824667 